\title{
Development of a reverse transcription quantitative polymerase chain reaction-based assay for broad coverage detection of African and Asian Zika virus lineages
}

\author{
Yang Yang ${ }^{1,2 \#}$, Gary Wong ${ }^{1,2 \#}$, Baoguo Ye ${ }^{3 \#}$, Shihua Li ${ }^{2}$, Shanqin $\mathrm{Li}^{1}$, Haixia Zheng1, Qiang Wang ${ }^{1,2}$, \\ Mifang Liang ${ }^{4}$, George F Gao ${ }^{1,2,5,6}$, Lei Liu ${ }^{1 凶}$, Yingxia Liu ${ }^{1 凶}$, Yuhai Bi ${ }^{1,2 \bowtie}$
}

1. Shenzhen Key Laboratory of Pathogen and Immunity, State Key Discipline of Infectious Disease, Shenzhen Third People's Hospital, Shenzhen 518112, China

2. CAS Key Laboratory of Pathogenic Microbiology and Immunology, Collaborative Innovation Center for Diagnosis and Treatment of Infectious Disease, Institute of Microbiology, Center for Influenza Research and Early-warning (CASCIRE), Chinese Academy of Sciences, Beijing 100101, China

3. China-Japan Union Hospital of Jilin University, Changchun 130033, China

4. Key Laboratory for Medical Virology, NHFPC, National Institute for Viral Disease Control and Prevention, China CDC, Beijing 102206, China

5. Office of Director-General, Chinese Center for Disease Control and Prevention, Beijing 102206, China

6. Savaid Medical School, University of Chinese Academy of Sciences, Beijing 100049, China

The Zika virus (ZIKV) is an arbovirus that has spread rapidly worldwide within recent times. There is accumulating evidence that associates ZIKV infections with Guillain-Barré Syndrome (GBS) and microcephaly in humans. The ZIKV is genetically diverse and can be separated into Asian and African lineages. A rapid, sensitive, and specific assay is needed for the detection of ZIKV across various pandemic regions. So far, the available primers and probes do not cover the genetic diversity and geographic distribution of all ZIKV strains. To this end, we have developed a one-step quantitative reverse transcription polymerase chain reaction (qRT-PCR) assay based on conserved sequences in the ZIKV envelope $(E)$ gene. The detection limit of the assay was determined to be five RNA transcript copies and $2.94 \times 10^{-3} 50 \%$ tissue culture infectious doses $\left(\right.$ TCID $\left._{50}\right)$ of live ZIKV per reaction. The assay was highly specific and able to detect five different ZIKV strains covering the Asian and African lineages without nonspecific amplification, when tested against other flaviviruses. The assay was also successful in testing for ZIKV in clinical samples. Our assay represents an improvement over the current methods available for the detection ZIKV and would be valuable as a diagnostic tool in various pandemic regions.

KEYWORDS Flavivirus; Zika virus(ZIKV); molecular diagnostics; qRT-PCR 


\section{INTRODUCTION}

The Zika virus (ZIKV) was first identified in 1947 from a sentinel rhesus monkey during surveillance of yellow fever in Uganda (Dick et al., 1952). The virus was subsequently isolated in humans in Uganda and Tanzania in 1952 (Macnamara, 1954). The ZIKV belongs to the Flavivirus genus within the Flaviviridae family. Similar to other flaviviruses, ZIKV is a single-stranded positive RNA virus with a genome of approximately $10.8 \mathrm{~kb}$, containing a single open reading frame (ORF), flanked by two untranslated regions (UTR) located at the $5^{\prime}$ and $3^{\prime}$ ends of the genome (Kuno and Chang, 2007; Saiz et al., 2016). The single ORF encodes the viral polyprotein that is cleaved by cellular and viral proteases into three structural proteins: the capsid (C), premembrane/membrane (prM/M), and envelope (E); and seven non-structural proteins (NS1, NS2A, NS2B, NS3, NS4A, NS4B, and NS5) (Kuno and Chang, 2007; Saiz et al., 2016). Phylogenetic studies have shown that ZIKV can be separated into two major lineages, Asian and African, and that it shows the highest genome similarity to other mosquitoborne flaviviruses, such as dengue virus (DENV), West Nile virus (WNV) and Japanese encephalitis virus (JEV) (Lanciotti et al., 2008; Wang L. et al., 2016a). The reservoir for ZIKV is not clearly defined, but it is speculated that the virus is likely maintained in a primatemosquito-primate sylvatic cycle that includes nonhuman primates and/or humans, and a broad range of mosquitoes that mainly belong to the Aedes genus (Wolfe et al., 2001; Grard et al., 2010; Musso and Gubler, 2016).

For half a century after the discovery of ZIKV, only sporadic infections in humans were documented, mainly in Africa and Southeast Asia (Faye et al., 2014; Saiz et al., 2016). This might be partially due to the high frequency of asymptomatic infections (up to $80 \%$ ), as well as the mild, self-limiting nature of ZIKV fever, with clinical manifestations that could be mistaken for other infections (Duffy et al., 2009; Saiz et al., 2016). Clinical manifestations in symptomatic cases include fever, rash, arthralgia, headache, etc. that are similar to those of other arboviral infections, such as DENV and chikungunya virus (CHIKV) (Dick et al., 1952; Hamel et al., 2016). In 2015, an outbreak of ZIKV fever originated in Brazil (Faria et al., 2016), and as of January 5, 2017, over 70 countries and territories have reported continued mosquito-borne transmission of ZIKV within their borders (World Health Organization [WHO], 2017). Accumulating evidence suggests that ZIKV infection is associated with microcephaly of the fetus in pregnant women, as well as an increased incidence of Guillain-Barré Syndrome (GBS); moreover, the infection can be sexually transmitted and poses a potential risk of testicular damage (Govero et al., 2016; Lucchese and Kanduc,
2016; Ma et al., 2016; Malkki, 2016; Mlakar et al., 2016; Parra et al., 2016; WHO, 2016b; Wong et al., 2016). These findings suggest that ZIKV is more dangerous than previously thought. As such, the WHO declared ZIKV a public health emergency of international concern (WHO, 2016a).

Due to the general nature of disease symptoms, in addition to the co-circulation with DENV and CHIKV in many ZIKV-affected areas, accurate diagnosis of ZIKV fever is difficult (Dick et al., 1952; Hamel et al., 2016; Saiz et al., 2016). Virus isolation and serological methods are still commonly used as diagnostic tools, despite their shortcomings. For instance, ZIKV isolation is time consuming, as it requires days to grow the virus on permissible cell lines; whereas serological methods could have limited cross-reactivity with related flaviviruses (Hamel et al., 2016; Saiz et al., 2016) and are not indicative of current (active) ZIKV infection. Quantitative reverse transcription polymerase chain reaction (qRTPCR)-based assays are known for their ability to provide rapid, sensitive, and specific pathogen detection. Currently, the available primers and probes do not cover the genetic diversity and geographic distribution of all ZIKV strains (Lanciotti et al., 2008; Faye et al., 2013; Musso and Gubler, 2016). Furthermore, ZIKV displays high genetic diversity even within the same lineage and region (Shi et al., 2016; Zhang et al., 2016). To address this problem, we describe a novel qRT-PCR assay with broad coverage of ZIKV strains, including new circulating isolates.

\section{MATERIALS AND METHODS}

\section{Viruses and RNA extraction}

The DENV 1-4 strains were provided by Prof. Chengfeng Qin. Strains of the ZIKV isolates MR_766 and PRVABC59 were provided by Prof. Mifang Liang, and the PLCal_ZV strain was provided by Prof. Gary Kobinger (University of Laval and Public Health Agency of Canada). The yellow fever virus (YFV) BJ01 strain and ZIKV SZ_SMGC-1 and CAS01 strains were isolated by our group from previously imported cases to China. Viral stocks were prepared using Vero or C6/36 cell lines. The RNA was extracted from viral stocks using the QIAamp RNA Viral Kit (Qiagen, Heiden, Germany) and MagaBio plus Virus RNA Purification Kit (Automatic Nucleic Acid Purification System NPA-32+, BIOER, China) according to the manufacturer instructions. The RNA was washed with buffers AW1 and AW2, and eluted in $50 \mu \mathrm{L}$ of AVE buffer and stored at $-80{ }^{\circ} \mathrm{C}$ for subsequent use.

\section{Viral stock titration by $\mathrm{TCID}_{50}$}

Vero cells in $96-$-well plates were grown to $90 \%$ confluence and infected with 10 -fold serial dilutions of the cell supernatant for $1 \mathrm{~h}$ at $37^{\circ} \mathrm{C}$. The inoculum was then 
removed, and cells were overlaid with fresh DMEM plus $2 \%$ FBS. At 6 days post infection (dpi), plates were assessed for the lowest dilution at which $50 \%$ of the wells exhibited cytopathology. The TCID $_{50}$ values were calculated according to the Reed-Muench method (Reed and Muench, 1938).

\section{Primer and probe design}

The $E$ gene of ZIKV was chosen as the target for the primer design because of its unique characteristic that facilitates its differentiation from those of other flaviviruses. All sequences of the 81 ZIKV strains used in the present study were downloaded from the National Center for Biotechnology Information (NCBI) database (http://www.ncbi.nlm.nih.gov/genome/viruses/variation/ Zika/), and aligned using the Clustal X program (Thompson et al., 1997). Conserved ZIKV-specific sequences that were divergent from other flaviviruses were identified, and the primers (ZIKV-F/ZIKV-R) were designed using the Primer Premier 5 software. The probe (ZIKVP) was labeled with the fluorescent reporter dye 6-carboxyfluorescein (FAM) at the 5'-end and the fluorescent quencher dye 6-carboxytetramethylrhodamin (TAMRA) at the 3'-end. The sequences and genome positions of the primer and probe set are shown in Figure 1.

\section{Generation of RNA standards}

A section of the $E$ gene, 98 base pairs in size, was amplified with the primers ZIKV-F/ZIKV-R, and the product was purified using the Gene JET PCR Purification Kit (Thermo, MA, USA) and ligated to the pGEM-T vector
(Promega, Madison, USA). In vitro transcription was performed using the MEGAscript T7 Transcription Kit (Thermo, MA, USA) and quantified using the Nanodrop 2000 Spectrophotometer (Thermo, MA, USA). The RNA copy number (molecules/ $\mu \mathrm{L}$ ) was calculated using the following equation: $[\mathrm{C} \times \mathrm{A} / 330 \times \mathrm{L}]$, where $\mathrm{C}$ represents the concentration of RNA $(\mathrm{g} / \mathrm{mL})$ assessed by the optical density measurement; $\mathrm{A}$ is the Avogadro number $\left(6.023 \times 10^{23}\right) ; \mathrm{L}$ is the length of the synthetic RNA (number of nucleotides); and 330 is an approximation of the molecular weight of a nucleotide $(\mathrm{g} / \mathrm{mol})$.

\section{Clinical samples}

Urine and serum samples were obtained from two confirmed cases of ZIKV infection in China (Deng C. et al., 2016a; Deng YQ. et al., 2016b; Liu et al., 2016; Wang Q. et al., 2016b). The RNA was extracted using the QIAamp RNA Viral Kit (Qiagen, Heiden, Germany) according to manufacturer recommendations.

\section{Quantitative reverse transcription polymerase chain reaction}

The RNA samples were tested by qRT-PCR in an ABI QuantStudio 7 Real-Time cycler (Applied Biosystems, Foster City, USA). The One Step PrimeScript ${ }^{\mathrm{TM}}$ RT-PCR Kit (Takara, Dalian, China) was used as follows: $0.8 \mu \mathrm{L}$ enzyme mixture (including reverse transcriptase [RT] and Taq polymerase), $10 \mu \mathrm{L} 2 \times$ One Step RT-PCR buffer III, $0.4 \mu \mathrm{L}$ of each primer and probe $(20 \mu \mathrm{mol} / \mathrm{L})$, $0.4 \mu \mathrm{L}$ ROX Reference Dye II, $2.6 \mu \mathrm{L}$ RNase free water, and $5 \mu \mathrm{L}$ RNA (total $20 \mu \mathrm{L} /$ reaction mixture). Each

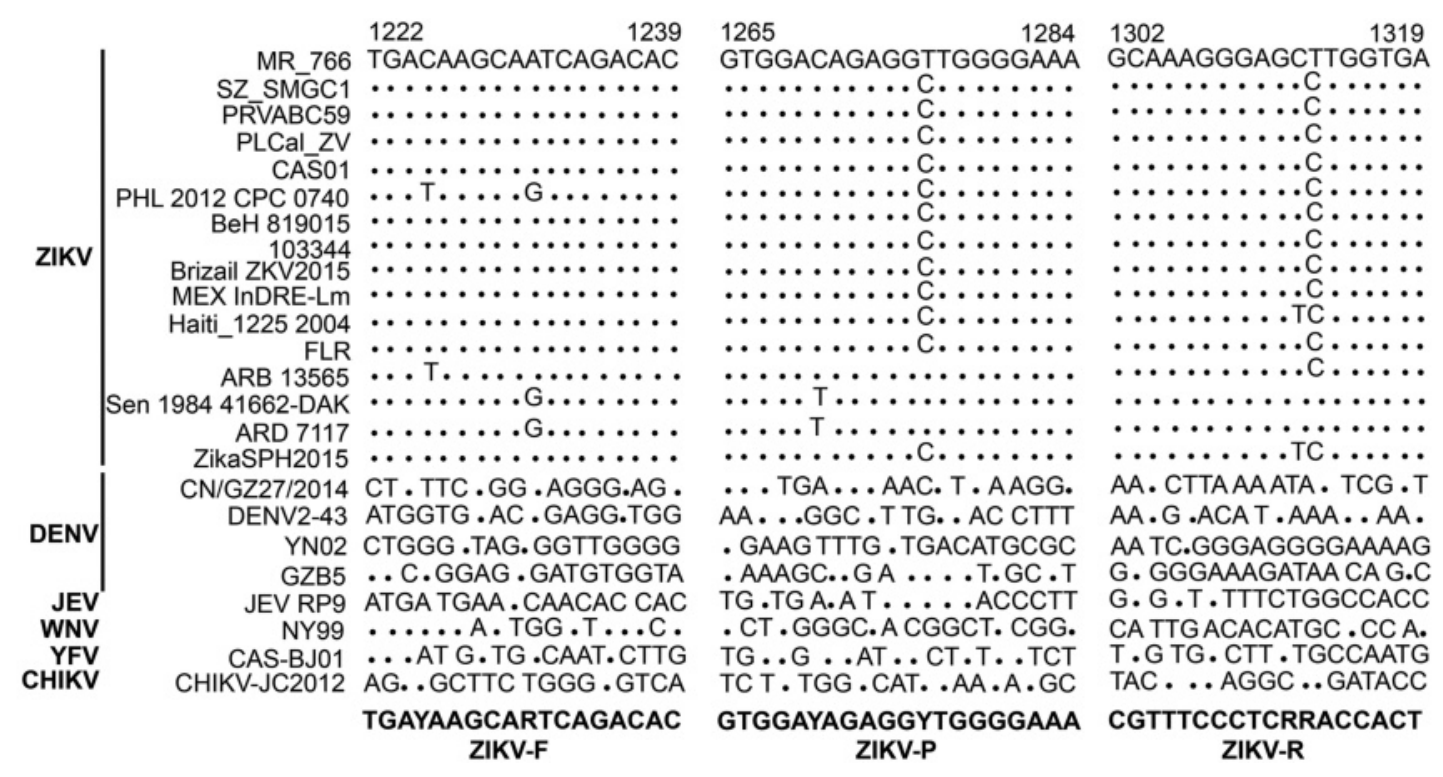

Figure 1. Conserved sequence selection for primer and probe design. The $E$ genes of 81 ZIKVs were downloaded for alignment; the most conserved regions that were divergent from other flaviviruses were selected for the primer and probe design. Alignment of the regions of designed primers and probe with reference strains of ZIKVs and other flaviviruses are shown. Dots indicate identity with the consensus sequence on top of the alignment. 
qRT-PCR run contained one negative and one positive control. The negative control consisted of water in place of the RNA sample. The positive control was ZIKV nucleic acid extracted from viral stocks, as described above. The qRT-PCR assay conditions were as follows: reverse transcription for $5 \mathrm{~min}$ at $42{ }^{\circ} \mathrm{C} ; 10 \mathrm{~s}$ at $95^{\circ} \mathrm{C}$ for reverse transcriptase inactivation and DNA polymerase activation followed by 40 cycles of $5 \mathrm{~s}$ at $95^{\circ} \mathrm{C}$; and $30 \mathrm{~s}$ at $55{ }^{\circ} \mathrm{C}$ (annealing-extension step). The data were analyzed using the QuantStudio ${ }^{\mathrm{TM}}$ Real-Time PCR Software (Applied Biosystems, Foster City, USA). Commercial qRT-PCR kits were also used for the detection of DENV, YFV, and ZIKV (Da An Gene Co., Ltd., Guangdong, China) following manufacturer instructions. All samples were analyzed in triplicate with three independent runs.

\section{RESULTS}

\section{Design of the primer-probe set}

The genomes of all ZIKVs were downloaded from the
NCBI database for alignment. After systematic analysis, we identified a highly conserved region of 98 nucleotides (nt) in length on the $E$ gene that was specific to ZIKV, but divergent from other flaviviruses. Based on the analysis, we designed the following primer-probe set for this conserved region: ZIKV-F (5'-TGAYAAGCARTCAGACAC-3'), ZIKV-R (5'-TCACCARRCTCCCTTTGC-3') and ZIKV-P (5'-FAM-GTGGAYAGAGGYTGGGGAAA-TAMRA-3'), which hybridized to positions 1222-1239, 1302-1319, and 1265-1284, respectively, in the ZIKV genome (Figure 1, as calculated from GenBank accession number AY632535). The primerprobe set was then used for ZIKV detection by the onestep qRT-PCR method, as described in the Materials and Methods section.

\section{Specificity of the qRT-PCR assay}

To test the specificity of our qRT-PCR method, different flaviviruses including DENV 1-4, YFV, and several ZIKV strains were used. All five ZIKVs, including both African and Asian lineages (Figure 2) could have been

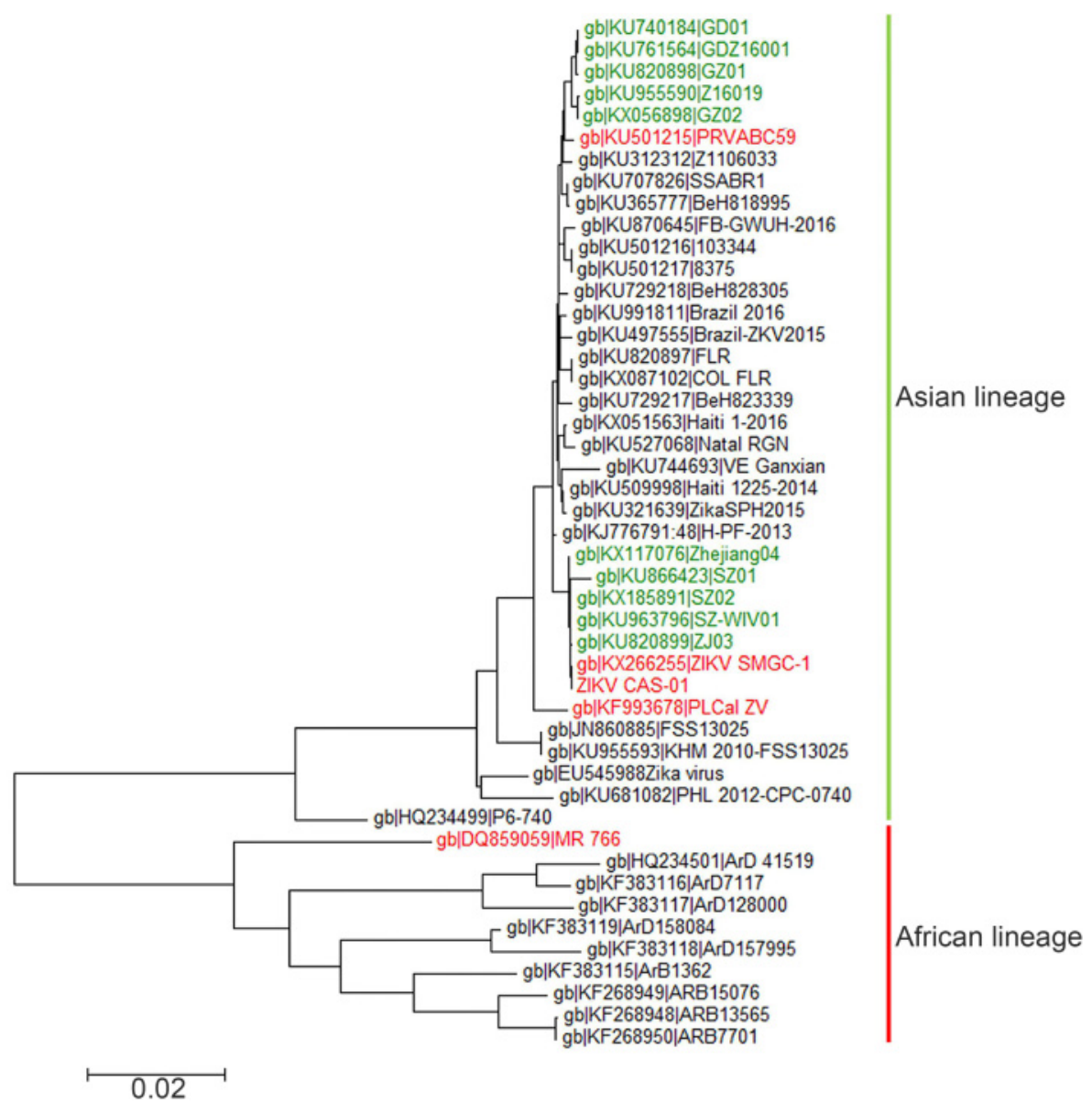

Figure 2. Phylogenetic analysis of ZIKVs. Genomes of ZIKVs were analyzed using the Mega 7 software. Strains of ZIKV imported into China and reference strains used in the present study are colored in green and red, respectively. 
detected by our primer-probe set (Table 1). In addition, with our primer-probe set, amplification was not observed in any of the RNA preparations from the DENV and YFV strains, or gene fragments of WNV. The novel qRT-PCR with the new primer-probe set displayed high specificity for ZIKVs without any amplification of other flaviviruses.

\section{Sensitivity of the qRT-PCR assay}

The detection limit of the novel qRT-PCR assay was evaluated using the quantitative RNA standards from a pGEM-T vector expressing the target sequence of the $E$ gene, and viral RNAs prepared from serial ten-fold dilutions of the five ZIKV stocks. Assays were performed in triplicate for both methods. The qRT-PCR method using the RNA standards as a template showed that cycle threshold $(\mathrm{Ct})$ values were linear between 1 (mean $\mathrm{Ct}$ value $=39.14)$ and $1 \times 10^{8}$ molecules $($ mean $\mathrm{Ct}$ value $=14.92)$. The regression coefficient $\left(R^{2}=0.999\right)$ indicated that over this range, the assay was both accurate and precise (Figure $3 \mathrm{~A}$ ). The detection limit was determined to be five RNA transcript copies per reaction, based on the standard curve (Figure 3A) and specific amplification curves (Figure 3B). Moreover, RNA samples were extracted from ten-fold serial dilutions of stock ZIKV ranging from $3.2 \times 10^{5}$ to $2.1 \times 10^{-2} \mathrm{TCID}_{50} / \mathrm{mL}$, and were used to test the detection limit. Results showed that the detection limit of the qRT-PCR assay was similar among the five ZIKV strains under evaluation, that is, between $2.94 \times 10^{-3}$ and $4.48 \times 10^{-3} \mathrm{TCID}_{50}$ per reaction $\left(2.94 \times 10^{-3} \mathrm{TCID}_{50}\right.$ for MR_766; $3.78 \times 10^{-3}$
$\mathrm{TCID}_{50}$ for CAS01; and $4.48 \times 10^{-3} \mathrm{TCID}_{50}$ for the other three strains). Viral titers were shown to correlate well with the obtained $\mathrm{Ct}$ values, ranging from 17.71 to 38.74 (Figure 4A-4E, Table 2). The Ct values across the quantitative range showed a standard deviation ranging from 0.01 to 0.58 (Table 2). According to our results, the specimen was considered positive if the $\mathrm{Ct}$ value was less than 38, and negative if it was undetermined. Any Ct values between 38 and 40 with typical amplification curves (Figure 3B) were considered indeterminate and positive if the repeat results were similar to the previous results, and this was confirmed by sequencing the amplicon.

\section{Evaluation of the qRT-PCR assay in clinical samples}

To assess the performance of the qRT-PCR assay in a clinical setting, tests were conducted on urine and serum samples from two confirmed ZIKV-infected cases imported to China, as mentioned in the Materials and Methods section. As expected, all samples tested positive for ZIKV and displayed comparatively lower $\mathrm{Ct}$ values with the qRT-PCR assay than those obtained with the commercial detection kit for ZIKV. However, no statistically significant differences were observed between the two results (Table 3 ).

\section{DISCUSSION}

In the present study, the detection limit was determined to be as low as five RNA transcript copies from a pGEM-T

Table 1. ZIKV and other flavivirus strains used in the present study

\begin{tabular}{|c|c|c|c|c|c|}
\hline $\begin{array}{l}\text { Flavivirus } \\
\text { species }\end{array}$ & Reference & Lineage & $\begin{array}{l}\text { GenBank } \\
\text { no. }\end{array}$ & $\begin{array}{l}\text { Virus titer } \\
\left(\mathrm{TCID}_{50} / \mathrm{mL}\right)\end{array}$ & RT-qPCR assays \\
\hline ZIKV & MR_766 & African & KX377335 & $2.1 \times 10^{6}$ & $14.75 \pm 0.22$ \\
\hline ZIKV & PRVABC59 & Asian & KX377337 & $3.2 \times 10^{4}$ & $20.22 \pm 0.16$ \\
\hline ZIKV & PLCal_ZV & Asian & KF993678 & $3.2 \times 10^{5}$ & $17.59 \pm 0.22$ \\
\hline ZIKV & SZ_SMGC-1 & Asian & KX266255 & $3.2 \times 10^{5}$ & $17.96 \pm 0.44$ \\
\hline ZIKV & CAS01 & Asian & NA & $2.7 \times 10^{5}$ & $18.59 \pm 0.23$ \\
\hline DENV & CN/GZ27/2014 & Serotype 1 & KP723473 & $N A^{c}$ & $U^{d}$ \\
\hline DENV & DENV2-43 & Serotype 2 & AF204178 & NA & $U$ \\
\hline DENV & YN02 & Serotype 3 & KF824903 & NA & $U$ \\
\hline DENV & GZB5 & Serotype 4 & AF289029 & NA & $U$ \\
\hline YFV & BJ01/2016 & $-{ }^{b}$ & KY495641 & NA & $U$ \\
\hline$W_{N} V^{a}$ & NY99 & $-^{\mathrm{b}}$ & NC_009942 & $1 \times 10^{6}($ copies $/ \mu \mathrm{L})$ & NA \\
\hline
\end{tabular}

Note: ZIKV, Zika virus; DENV, dengue virus; YFV, yellow fever virus; WNV, West Nile virus. ${ }^{a}$ The synthetic envelope gene was used instead of the live virus; ${ }^{\mathrm{b}}$ Not applicable; ${ }^{\mathrm{C}}$ Not available; ${ }^{\mathrm{d}}$ Undetected. The Ct values of the commercial kits for DENVs (CN/GZ27/2014, DENV2-43, YN02, and GZB5) and YFV were 17.22, 12.18, 15.23, 16.42, and 15.59, respectively. 
A

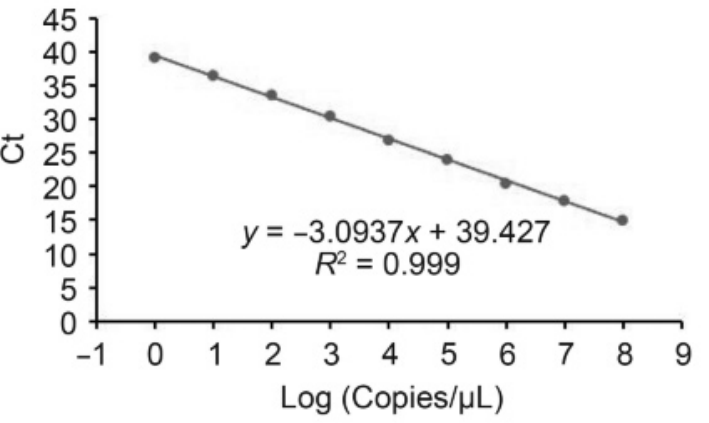

B

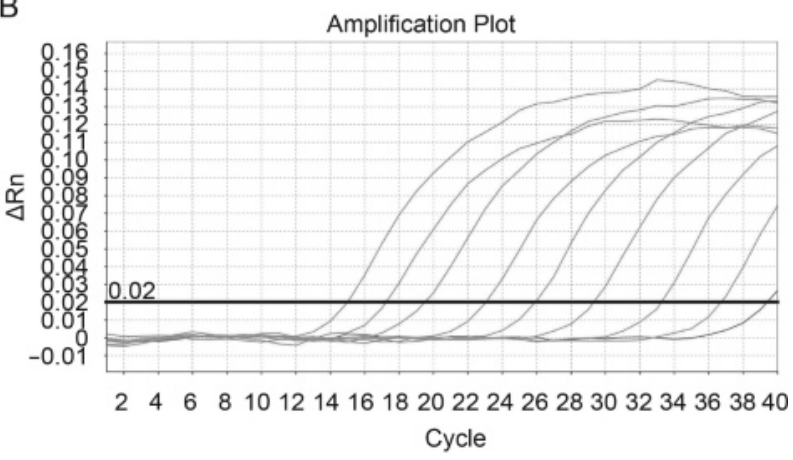

Figure 3. Sensitivity of the qRT- PCR assay using synthetic ZIKV RNA. (A) Standard curve for ten-fold serial dilution of synthetic ZIKV RNA. The log number of ZIKV RNA transcripts (Copies/ $\mu \mathrm{L}$ ) is expressed linearly on the $x$-axis, whereas $C t$ values obtained from qRT-PCR are expressed linearly on the $y$-axis. (B) Representative amplification curves of the different concentrations of synthetic ZIKV RNA. vector expressing the target sequence, and $2.94 \times 10^{-3}$ TCID $_{50}$ of live ZIKV per reaction, with high accuracy and precision $\left(\mathrm{R}^{2}=0.999\right)$. These findings reflect greater sensitivity than the previously developed qRT-PCR targeting NS5 gene and other traditional RT-PCR assays that target the $E$ gene (Lanciotti et al., 2008; Faye et al., 2013; Basarab et al., 2016). The difference in abundance of the $E$ and NS5 genes in the ZIKV virion might influence the sensitivity of qRT-PCR detection. Currently, diagnosis of ZIKV infection is mainly based on the detection of ZIKV RNA during the first few days after the onset of symptoms (Musso and Gubler, 2016). According to previous studies, ZIKV RNA can be detected in several types of bodily fluids, including blood, urine, saliva, breast milk, and semen (Musso and Gubler, 2016). In symptomatic patients, viremia ranges from $7.28 \times 10^{6}$ to $9.3 \times 10^{8}$ copies $/ \mathrm{mL}$, and in asymptomatic patients, from $2.5 \times 10^{3}$ to $8 \times 10^{6}$ copies $/ \mathrm{mL}$ (Besnard et al., 2014; Waehre et al., 2014; Aubry et al., 2016; Musso and Gubler, 2016). In urine, viral loads range from $3.8 \times$ $10^{3}$ to $2.2 \times 10^{8}$ copies $/ \mathrm{mL}$ with a greater persistence than in serum ( 10 to $>20$ days, and $>7$ days, once it becomes undetectable in serum) (Besnard et al., 2014; Gourinat et al., 2015; Musso et al., 2015). Accordingly, our assay qualifies for the surveillance of ZIKV from various types of clinical samples without nonspecific amplification of other flaviviruses. In comparison to qRT-PCR, ELISAs are limited by cross-reactivity with other flaviviruses, due to the close relatedness to, and co-circulation of other flaviviruses in ZIKV endemic regions. Furthermore, detection of ZIKV is best achieved during the acute-phase; however, it is difficult to
A

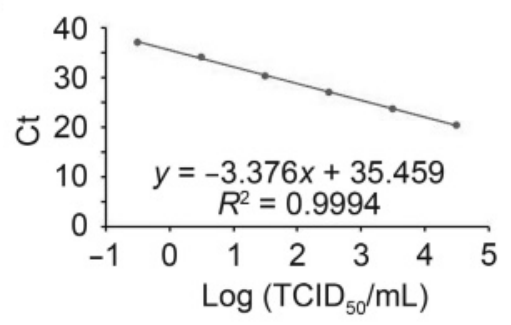

D
B

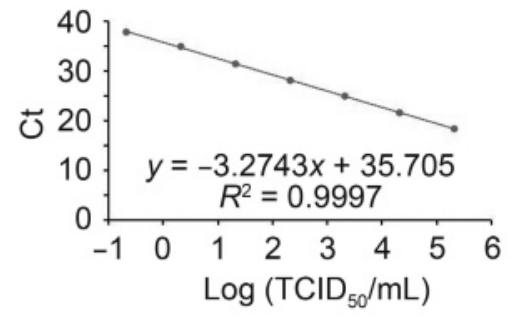

C

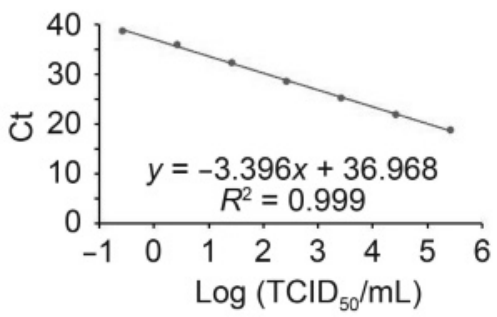

E
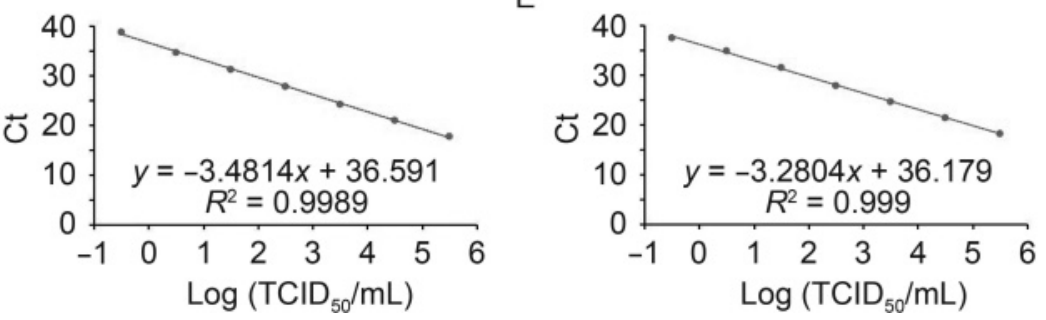

Figure 4. Sensitivity of the qRT- PCR assay using ZIKV viral RNAs. (A-F) Standard curves for ten-fold serial dilutions of stock ZIKV strains PRVABC59, MR_766, CAS01, PLCal_ZV, and SZ_SMGC-1, respectively. The log number of live ZIKV $\left(\mathrm{TCID}_{50} / \mathrm{mL}\right)$ is expressed linearly on the $x$-axis, whereas Ct values are expressed linearly on the $y$-axis. 
Table 2. Sensitivity of the qRT-PCR assay for ZIKV RNA detection

\begin{tabular}{|c|c|c|c|c|c|}
\hline \multirow{2}{*}{ Serial dilution ${ }^{a}$} & \multicolumn{5}{|l|}{ Ct Values } \\
\hline & MR_766 & CAS01 & PLCal_ZV & SZ_SMGC-1 & PRVABC59 \\
\hline Viral stock & $17.92 \pm 0.04$ & $18.69 \pm 0.23$ & $17.71 \pm 0.40$ & $18.16 \pm 0.39$ & $20.32 \pm 0.06$ \\
\hline $10^{-1}$ & $21.13 \pm 0.18$ & $21.80 \pm 0.25$ & $20.95 \pm 0.01$ & $21.36 \pm 0.42$ & $23.62 \pm 0.18$ \\
\hline $10^{-2}$ & $24.49 \pm 0.06$ & $25.15 \pm 0.05$ & $24.19 \pm 0.13$ & $24.62 \pm 0.48$ & $26.96 \pm 0.02$ \\
\hline $10^{-3}$ & $27.71 \pm 0.11$ & $28.51 \pm 0.09$ & $27.80 \pm 0.10$ & $27.86 \pm 0.45$ & $30.26 \pm 0.04$ \\
\hline $10^{-4}$ & $31.01 \pm 0.18$ & $32.25 \pm 0.10$ & $31.21 \pm 0.05$ & $31.51 \pm 0.61$ & $34.06 \pm 0.10$ \\
\hline $10^{-5}$ & $34.52 \pm 0.01$ & $35.89 \pm 0.58$ & $34.64 \pm 0.10$ & $34.86 \pm 0.36$ & $37.03 \pm 0.31$ \\
\hline $10^{-6}$ & $37.75 \pm 0.22$ & $38.66 \pm 0.54$ & $38.74 \pm 0.25$ & $37.48 \pm 0.13$ & Neg \\
\hline $10^{-7}$ & $\mathrm{Neg}^{\mathrm{b}}$ & Neg & $\mathrm{Neg}$ & $\mathrm{Neg}$ & $\mathrm{Neg}$ \\
\hline
\end{tabular}

Note: ${ }^{a}$ The titers of stock ZIKV were $2.1 \times 10^{5} \mathrm{TCID}_{50} / \mathrm{mL}$ (MR_766), $2.7 \times 10^{5} \mathrm{TCID}_{50} / \mathrm{mL}(\mathrm{CAS} 01), 3.2 \times 10^{5} \mathrm{TCID}_{50} / \mathrm{mL}$ (SZ_SMGC-1), $3.2 \times 10^{5} \mathrm{TCID}_{50} / \mathrm{mL}$ (PLCal_ZV) and $3.2 \times 10^{4} \mathrm{TCID}_{50} / \mathrm{mL}$ (PRVABC59), respectively; ${ }^{b}$ Negative.

Table 3. Detection of ZIKV in clinical samples

\begin{tabular}{lllll}
\multirow{2}{*}{ Samples } & \multicolumn{2}{l}{ qRT-PCR assays } & & \\
\cline { 3 - 4 } & & Our method & Commercial kit & $P^{\mathrm{a}}$ \\
\hline Patient 1 & Serum & $29.67 \pm 0.82$ & $30.63 \pm 0.13$ & 0.1146 \\
& Urine & $29.54 \pm 0.61$ & $30.47 \pm 0.12$ & 0.0606 \\
Patient 2 & Serum & $26.71 \pm 0.58$ & $27.66 \pm 0.84$ & 0.1823
\end{tabular}

Note: ${ }^{a}$ Data were analyzed using the Student's $t$-test, and Pvalues represent a comparison of our method with that of the commercial kit.

determine the period of the onset of symptoms, as the majority of cases are asymptomatic (Hamel et al., 2016; Saiz et al., 2016).

In conclusion, we have developed a rapid, specific qRT-PCR assay with high sensitivity and broad coverage of circulating ZIKV strains (both African and Asian lineages). This assay would be of value in surveillance efforts across various regions of the outbreak.

\section{ACKNOWLEDGMENTS}

This work was supported by the National Science and Technology Major Project (2016ZX10004222), the Sanming Project of Medicine in Shenzhen (ZDSYS2015 04301534057), the Key specialized fund for infectious diseases in Shenzhen City (No. 201161), the intramural special grant for influenza virus research from the Chinese Academy of Sciences (KJZD-EW-L09 and KJZD-EWL15), and the Shenzhen Science and Technology Research and Development Project (JCYJ20160427151920801 and JCYJ20160427153238750). G.F.G. is a leading principal investigator of the National Natural Science Foundation of China (NSFC) Innovative Research Group
(81621091). Y.B. is supported by the Youth Innovation Promotion Association of Chinese Academy of Sciences (CAS) (2017122). G.W. is the recipient of a Banting Postdoctoral Fellowship from the Canadian Institutes of Health Research (CIHR) and the President's International Fellowship Initiative from the CAS. We thank Dr. Chengfeng Qin and Gary Kobinger for supplying strains of DENVs and ZIKVs.

\section{COMPLIANCE WITH ETHICS GUIDELINES}

The authors declared that they have no conflict of interest. The studies have been approved by our institutional research ethics committee, and written informed consent was obtained from all patients.

\section{AUTHOR CONTRIBUTIONS}

YHB and YY designed the experiments. YY, GW, BGY, YHB, SHL, SQL, HXZ and QW carried out the experiments. YY, YHB and GW analyzed the data. YXL, LL, MFL and GFG acquired the clinical samples and provided scientific input. YY, GW and YHB wrote the paper. All authors read and approved the final manuscript.

\section{REFERENCES}

Aubry M, Richard V, Green J, Broult J, Musso D. 2016. Inactivation of Zika virus in plasma with amotosalen and ultraviolet $\mathrm{A}$ illumination. Transfusion, 56: 33-40.

Basarab M, Bowman C, Aarons EJ, Cropley I. 2016. Zika virus. BMJ, 352: i1049.

Besnard M, Lastere S, Teissier A, Cao-Lormeau V, Musso D. 2014. Evidence of perinatal transmission of Zika virus, French Polynesia, December 2013 and February 2014. Euro Surveill, 19. pii: 20751.

Deng C, Liu S, Zhang Q, Xu M, Zhang H, Gu D, Shi L, He J, Xiao 
G, Zhang B. 2016a. Isolation and characterization of Zika virus imported to China using C6/36 mosquito cells. Virol Sin, 31: $176-179$.

Deng YQ, Zhao H, Li XF, Zhang NN, Liu ZY, Jiang T, Gu DY, Shi L, He JA, Wang HJ, Sun ZZ, Ye Q, Xie DY, Cao WC, Qin CF. 2016b. Isolation, identification and genomic characterization of the Asian lineage Zika virus imported to China. Sci China Life Sci, 59: 428-430.

Dick GW, Kitchen SF, Haddow AJ. 1952. Zika virus. I. Isolations and serological specificity. Trans R Soc Trop Med Hyg, 46: 509-520.

Duffy MR, Chen TH, Hancock WT, Powers AM, Kool JL, Lanciotti RS, Pretrick M, Marfel M, Holzbauer S, Dubray C, Guillaumot L, Griggs A, Bel M, Lambert AJ, Laven J, Kosoy O, Panella A, Biggerstaff BJ, Fischer M, Hayes EB. 2009. Zika virus outbreak on Yap Island, Federated States of Micronesia. N Engl J Med, 360: 2536-2543.

Faria NR, Azevedo Rdo S, Kraemer MU, Souza R, Cunha MS, Hill SC, Theze J, Bonsall MB, Bowden TA, Rissanen I, et al. 2016. Zika virus in the Americas: Early epidemiological and genetic findings. Science, 352: 345-349.

Faye O, Faye O, Diallo D, Diallo M, Weidmann M, Sall AA. 2013. Quantitative real-time PCR detection of Zika virus and evaluation with field-caught mosquitoes. Virol J, 10: 311.

Faye O, Freire CC, Iamarino A, Faye O, de Oliveira JV, Diallo M, Zanotto PM, Sall AA. 2014. Molecular evolution of Zika virus during its emergence in the 20(th) century. PLoS Negl Trop Dis, 8: e2636.

Gourinat AC, O'Connor O, Calvez E, Goarant C, DupontRouzeyrol M. 2015. Detection of Zika virus in urine. Emerg Infect Dis, 21: 84-86.

Govero J, Esakky P, Scheaffer SM, Fernandez E, Drury A, Platt DJ, Gorman MJ, Richner JM, Caine EA, Salazar V, Moley KH, Diamond MS. 2016. Zika virus infection damages the testes in mice. Nature, 540: 438-442.

Grard G, Moureau G, Charrel RN, Holmes EC, Gould EA, de Lamballerie X. 2010. Genomics and evolution of Aedes-borne flaviviruses. J Gen Virol, 91: 87-94.

Hamel R, Liegeois F, Wichit S, Pompon J, Diop F, Talignani L, Thomas F, Despres P, Yssel H, Misse D. 2016. Zika virus: epidemiology, clinical features and host-virus interactions. Microbes Infect, 18: 441-449.

Kuno G, Chang GJ. 2007. Full-length sequencing and genomic characterization of Bagaza, Kedougou, and Zika viruses. Arch Virol, 152: 687-696.

Lanciotti RS, Kosoy OL, Laven JJ, Velez JO, Lambert AJ, Johnson AJ, Stanfield SM, Duffy MR. 2008. Genetic and serologic properties of Zika virus associated with an epidemic, Yap State, Micronesia, 2007. Emerg Infect Dis, 14: 1232-1239.

Liu L, Wu W, Zhao X, Xiong Y, Zhang S, Liu X, Qu J, Li J, Nei K, Liang M. 2016. Complete Genome Sequence of Zika Virus from the First Imported Case in Mainland China. Genome Announc, 4. pii: e00291-16.

Lucchese G, Kanduc D. 2016. Zika virus and autoimmunity: From microcephaly to Guillain-Barre syndrome, and beyond. Autoimmun Rev, 15: 801-808.

Ma W, Li S, Ma S, Jia L, Zhang F, Zhang Y, Zhang J, Wong G, Zhang S, Lu X, Liu M, Yan J, Li W, Qin C, Han D, Qin C, Wang N, Li X, Gao GF. 2016. Zika Virus Causes Testis Damage and Leads to Male Infertility in Mice. Cell, 167: 15111524.

Macnamara FN. 1954. Zika virus: a report on three cases of human infection during an epidemic of jaundice in Nigeria. Trans R Soc Trop Med Hyg, 48: 139-145.
Malkki H. 2016. CNS infections: Zika virus infection could trigger Guillain-Barre syndrome. Nat Rev Neurol, 12: 187.

Mlakar J, Korva M, Tul N, Popovic M, Poljsak-Prijatelj M, Mraz J, Kolenc M, Resman Rus K, Vesnaver Vipotnik T, Fabjan Vodusek V, Vizjak A, Pizem J, Petrovec M, Avsic Zupanc T. 2016. Zika Virus Associated with Microcephaly. N Engl J Med, 374: 951-958.

Musso D, Gubler DJ. 2016. Zika Virus. Clin Microbiol Rev, 29: 487-524.

Musso D, Roche C, Robin E, Nhan T, Teissier A, Cao-Lormeau VM. 2015. Potential sexual transmission of Zika virus. Emerg Infect Dis, 21: 359-361.

Parra B, Lizarazo J, Jimenez-Arango JA, Zea-Vera AF, GonzalezManrique G, Vargas J, Angarita JA, Zuniga G, Lopez-Gonzalez R, Beltran CL, et al. 2016. Guillain-Barre Syndrome Associated with Zika Virus Infection in Colombia. N Engl J Med, 375: 1513-1523.

Reed LJ, Muench H. 1938. A simple method of estimating fifty percent endpoints. Am J Hyg, 27: 493-497.

Saiz JC, Vazquez-Calvo A, Blazquez AB, Merino-Ramos T, Escribano-Romero E, Martin-Acebes MA. 2016. Zika Virus: the Latest Newcomer. Front Microbiol, 7: 496.

Shi W, Zhang Z, Ling C, Carr MJ, Tong Y, Gao GF. 2016. Increasing genetic diversity of Zika virus in the Latin American outbreak. Emerg Microbes Infect, 5: e68.

Thompson JD, Gibson TJ, Plewniak F, Jeanmougin F, Higgins DG. 1997. The CLUSTAL_X windows interface: flexible strategies for multiple sequence alignment aided by quality analysis tools. Nucleic Acids Res, 25: 4876-4882.

Waehre T, Maagard A, Tappe D, Cadar D, Schmidt-Chanasit J. 2014. Zika virus infection after travel to Tahiti, December 2013. Emerg Infect Dis, 20: 1412-1414.

Wang L, Valderramos SG, Wu A, Ouyang S, Li C, Brasil P, Bonaldo M, Coates T, Nielsen-Saines K, Jiang T, Aliyari R, Cheng G. 2016a. From Mosquitos to Humans: Genetic Evolution of Zika Virus. Cell Host Microbe, 19: 561-565.

Wang Q, Yang Y, Zheng HX, Bi YH, Song JD, Li LQ, Gu DY, Wang PY, Li SH, Liu S, Zhao YZ, Liu L, Gao GF, Liu YX. 2016 b. Genetic and biological characterization of $\mathrm{Zika}$ virus from human cases imported through Shenzhen Port. Chinese Science Bulletin, 61: 2463-2474.

WHO 2016a, posting date. WHO statement on the first meeting of the International Health Regulations (2005) (IHR 2005) Emergency Committee on Zika virus and observed increase in neurological disorders and neonatal malformations. Available: http://www.who.int/mediacentre/news/statements/2016/1stemergency-committee-zika/en/. Accessed 18 October 2016.

WHO 2016b, posting date. Zika virus and complications. Available: http://www.who.int/emergencies/zika-virus/en/. Accessed 18 October 2016.

WHO 2017, posting date. Zika Situation Report. Available: http://www.who.int/emergencies/zika-virus/situation-report/05january-2017/en/. Accessed 6 May 2017.

Wolfe ND, Kilbourn AM, Karesh WB, Rahman HA, Bosi EJ, Cropp BC, Andau M, Spielman A, Gubler DJ. 2001. Sylvatic transmission of arboviruses among Bornean orangutans. Am J Trop Med Hyg, 64: 310-316.

Wong G, Li S, Liu L, Liu y, Bi Y. 2017. Zika virus in the testes: should we be worried?. Protein Cell, 8: 162-164.

Zhang Y, Chen W, Wong G, Bi Y, Yan J, Sun Y, Chen E, Yan H, Lou X, Mao H, Xia S, Gao GF, Shi W, Chen Z. 2016. Highly diversified Zika viruses imported to China, 2016. Protein Cell, 7: 461-464. 